\title{
Study of Wind Turbine based Variable Reluctance Generator using Hybrid FEMM-MATLAB Modeling
}

\author{
Tariq Benamimour, Amar Bentounsi, Hind Djeghloud
}

LGEC, Lab. of Electrotechnique Dept., University of Mentouri Constantine, Algeria

\begin{abstract}
Article Info
Article history:

Received Jan 3, 2016

Revised Mar 21, 2016

Accepted Jun 13, 2016

\section{Keyword:}

Finite element analysis

Matlab/simulink

Modeling and simulation

Variable reluctance generator

Wind turbine

ABSTRACT

Based on exhaustive review of the state of the art of the electric generators fitted to Wind Energy Conversion System (WECS), this study is focused on an innovative machine that is a Variable Reluctance Generator (VRG). Indeed, its simple and rugged structure (low cost), its high torque at low speed (gearless), its fault-tolerance (lowest maintenance), allow it to be a potential candidate for a small wind power application at variable wind speed. For better accuracy, a finite element model of a studied doubly salient VRG is developed using open source software FEMM to identify the electromagnetic characteristics such as linkage flux, torque or inductance versus rotor position and stator excitation. The obtained data are then transferred into look-up tables of MATLAB/Simulink to perform various simulations. Performance of the proposed wind power system is analyzed for several parameters and results are discussed.
\end{abstract}

Copyright $@ 2017$ Institute of Advanced Engineering and Science. All rights reserved.

\section{Corresponding Author:}

Tariq Benamimour,

LGEC, Lab. of Electrotechnique Dept.,

University of Mentouri Constantine,

Tel/Fax: +213 31819013, Algeria.

Email: tarekbenamimourelt@yahoo.fr

\section{INTRODUCTION}

Emerged recently in a context of energy crisis and rising pollution, the concept of sustainable development has contributed to the development of renewable energies. Among the alternative resources, wind power has seen the strongest growth. Various wind energy conversion systems (WECS) have been proposed in association with different structures of electric generators where the major requirements are: high power density, efficiency, high reliability, lowest maintenance, reduction of the system parts (gearless), reasonable cost and other market criteria. The potential electrical generators candidates for WECS which may satisfy the above criteria are standard self excited induction generator (SEIG), doubly-fed induction generator (DFIG), permanent magnetic synchronous generator (PMSG) and, recently, a switched reluctance machine (SRM) used either in high speed drive or low speed generator [1-4]. In a comparative study of electrical generators fitted to wind turbine systems, the authors in [5] conclude that the PMSG seems to be the most adapted candidate as illustrated in the Table 1 below taken from this reference, where the evaluation is based in the main characteristics of the WECS, each them is graded from 1 to 5 points. Recently, due to numerous advantages (simple structure, robustness, high performance, low cost), an innovative variable reluctance generator (VRG) [6-14] has been recognized to have potential for wind power applications. This explains our interest in the study of this type of generator.

The main contribution of this work is related to an original numerical-analytical approach carried out under coupled FEMM-MATLAB user-friendly softwares used to model with better accuracy the studied 6/4 three-phase VRG fed with asymmetric half bridge converter [15]. 
The paper is organized as follows: Section 2 describes the main characteristics of wind turbine and the finite element modeling of the studied VRG. In Section 3, the simulation process of WECS using MATLAB/Simulink is presented and results are discussed. The paper concludes in Section 4.

Table 1. Wind Power Systems Evaluation [5]

\begin{tabular}{|c|c|c|c|c|}
\hline $\begin{array}{c}\text { Generation } \\
\text { Systems }\end{array}$ & $\begin{array}{c}\text { DFIG } \\
\text { Characteristics }\end{array}$ & IG & PMSG & SRG \\
\hline Power Density & 4.5 & 3.5 & 5 & 3.5 \\
Efficiency & 4 & 3.5 & 5 & 3.5 \\
Controllability & 5 & 4 & 5 & 4 \\
Reliability & 4 & 3 & 4 & 5 \\
Technological maturity & 5 & 5 & 4 & 4 \\
weight & 3.5 & 3.5 & 5 & 2 \\
Cost & 4 & 4 & 3 & 5 \\
\hline \multirow{2}{*}{ Total } & 30 & 26.5 & 31 & 26 \\
\hline
\end{tabular}

\section{MODELING OF WIND ENERGY CONVERSION SYSTEM}

The wind energy conversion system (WECS) shown in Figure 1 is relatively standard. Usually, it consists of four parts:

a. The wind turbine converts wind energy into kinetic energy.

b. The gearbox to adapt the speed of the turbine to that of the generator.

c. The generator that converts mechanical energy into electrical energy.

d. The static converter DC-AC which will not be examined in this study.

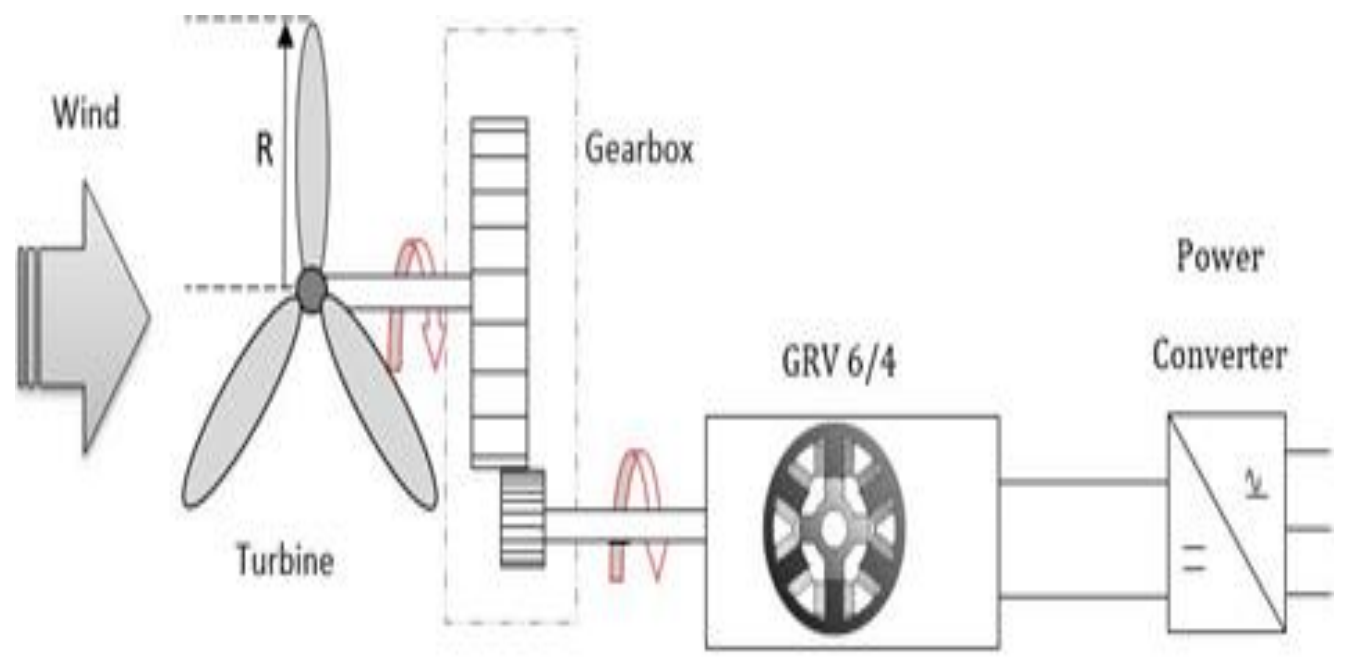

Figure 1. Wind Energy Conversion System

In order to perform simulations under MATLAB/SIMULINK environment, the mathematical model of the WECS is represented by the synoptic diagram shown in Figure 2. 


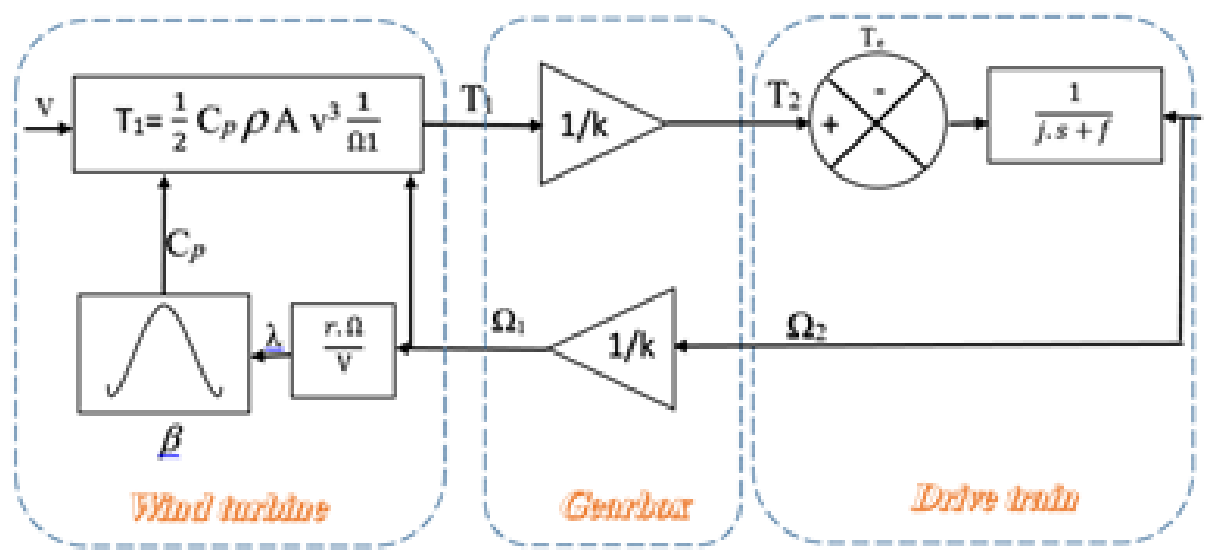

Figure 2. Synoptic Diagram of the WECS

\subsection{Main Characteristics of Wind Turbine}

The wind power converted into mechanical power by the turbine is given by (1):

$$
P_{m}=\frac{1}{2} C_{p}(\lambda, \beta) \rho A v^{3}
$$

where $\rho$ is the air density $\left(\mathrm{kg} / \mathrm{m}^{3}\right), \mathrm{A}=\pi \mathrm{R}^{2}$ is the turbine swept area $\left(\mathrm{m}^{2}\right), \mathrm{R}$ is the radius of rotor blade $(\mathrm{m})$, $\mathrm{Cp}(\lambda, \beta)$ is the power coeficient function of the blade pitch angle $\beta$ (deg) and the tip-speed ratio (TSR) given by:

$$
\lambda=\frac{R \Omega_{t}}{v}
$$

where $\Omega_{\mathrm{t}}$ is the rotational speed of the turbine ( $\left.\mathrm{rad} / \mathrm{s}\right)$

Hence, the TSR $(\lambda)$ can be controlled by the rotational speed of generator. The coefficient $\mathrm{C}_{\mathrm{p}}$ can be represented by the following relationship [16]:

$$
C_{p}(\lambda, \beta)=0.5176 \cdot\left[\frac{116}{\lambda_{i}}-0.4 \beta-5\right] \cdot e^{\frac{-21}{\lambda_{i}}}+0.0068 \lambda
$$

with:

$$
\frac{1}{\lambda_{i}}=\frac{1}{\lambda+0.08 \beta}-\frac{0.035}{\beta^{3}+1}
$$

The characteristic of the generated power vs. rotational speed according to the wind speed is represented in Figure 3. The power coefficient vs. tip speed ratio for different values of pitch angle is depicted in Figure 4. The ideal curve of power vs. wind speed shown in Figure 5 illustrates one of the major factors affecting the performance of the wind power through three distinct zones:

a. Zone I: below cut-in wind speed, the turbine does not produce power.

b. Zone II: at cut-in wind speed, the system begins to produce power $\left(\mathrm{P} \sim \mathrm{V}^{3}\right)$ until nominal wind speed.

c. Zone III: the turbine produces constant power (pitch control).

d. Zone IV: at cut-off wind speed, the system stops.

To extract the maximum power from the wind turbine, it is necessary to adjust the rotor speed ( $\Omega$ ) at optimum value of TSR $\left(\lambda_{\text {opt }}\right)$ with wind speed variation $(v)$; this is achieved in zone II. Table 2 is shows parameters of wind turbine 


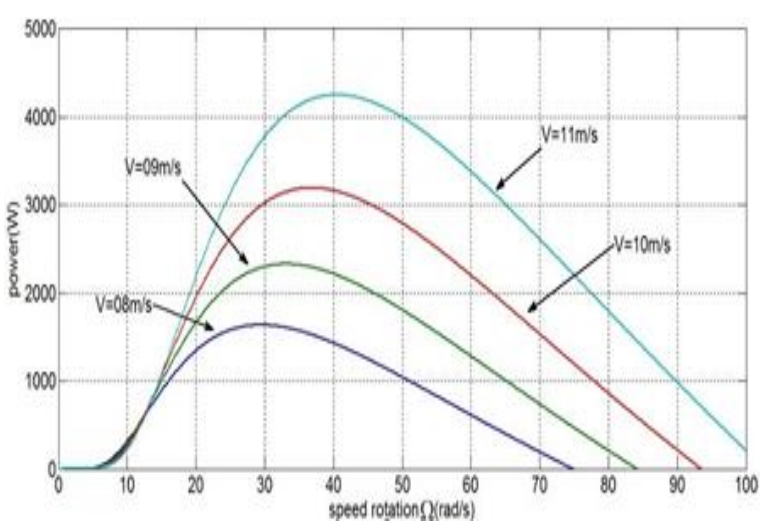

Figure 3. Mechanic Power Characteristic vs. Rotating Speed of the Rotor for different Values of Wind Speed

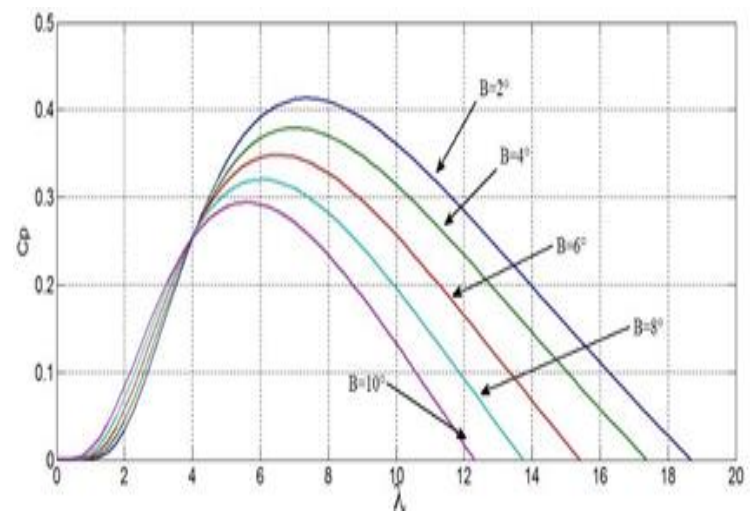

Figure 4. Power Coefficient vs. Tip Speed Ratio for different Values of $\beta$

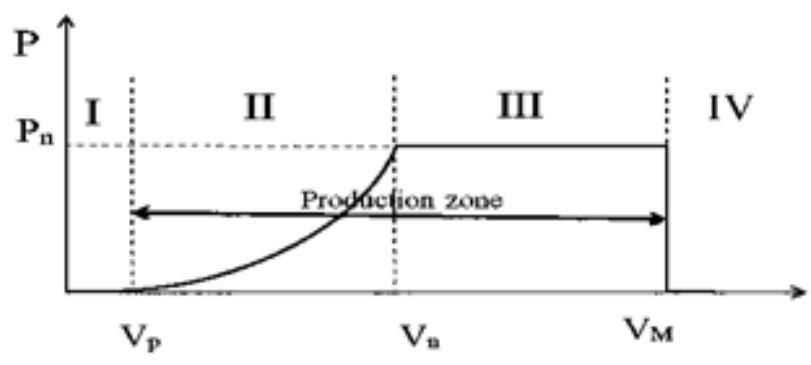

Figure 5. Typical Power Curve of a Wind Turbine

Table 2. Parameters of Wind Turbine

\begin{tabular}{cc}
\hline Parameter & Value \\
\hline Cut-in speed & $4 \mathrm{~m} / \mathrm{s}$ \\
Cut-out speed & $30 \mathrm{~m} / \mathrm{s}$ \\
Rated wind speed & $8 \mathrm{~m} / \mathrm{s}$ \\
Rated power & $3 \mathrm{~kW}$ \\
Blade radius & $2 \mathrm{~m}$ \\
Optimal power coef. & 0.4131 \\
Optimal TSR & 7.5 \\
\hline
\end{tabular}

\subsection{Mathematical Model of the Generator}

\subsubsection{Operating Principle}

The studied three-phase 6/4 Variable Reluctance Generator has six salient poles on the stator and four salient poles on the rotor as depicted in Figure 6. The rotor has no windings or magnets while the stator windings are distributed as three pairs connected in series and fed with asymmetric half bridge converter where each phase is represented in Figure 7. There are two operating sequences: (i) excitation sequence by switching Q1 and Q2; (ii) generation sequence to supply the load via the diodes D1 and D2.

\subsubsection{Basic Equations}

The generated voltage per stator $\mathrm{k}$-phase is expressed by:

$$
(-) V_{k}=r_{k} i_{k}+L_{k}\left(\theta, i_{k}\right) \cdot \frac{d i_{k}}{d t}+\omega i_{k} \frac{\partial L_{k}\left(\theta, i_{k}\right)}{\partial \theta}
$$

where $r_{k}$ is the phase resistance, $i_{k}$ is the phase current, $L_{k}$ is the incremental inductance and $\omega$ is the angular speed $(\mathrm{rad} / \mathrm{s})$ of generator. The third term of equation (5) represents the induced EMF which depends essentially on the rotational speed $\omega$ (we assume that the current and inductance slope are constant). 
The electromagnetic torque per k-phase is expressed by:

$$
T_{k}=\frac{1}{2} i_{k}^{2} \frac{\partial L_{k}(\theta)}{\partial \theta}
$$

From (6) we can conclude that the instantaneous torque is positive for increasing inductance (motor) and negative for decreasing inductance (generator) as shown in Figure 8.

\subsubsection{Analytical Model of Inductance}

The rotation of the rotor poles (free from windings and magnets) with respect to the excited stator poles varies the inductance of the generator periodically from maximum at the aligned position, $\mathrm{L}_{\max }$, to minimum at the unaligned position, $\mathrm{L}_{\text {min }}$. Usually, the fundamental component of the non-linear inductance is approximated by series Fourier expressed by:

$$
L_{k}(\theta)=L_{0}+L_{1} \cdot \cos \left(N_{r} \theta\right)
$$

where $\mathrm{L}_{0}=\left(\mathrm{L}_{\max }+\mathrm{L}_{\min }\right) / 2$ and $\mathrm{L}_{1}=\left(\mathrm{L}_{\max }-\mathrm{L}_{\min }\right) / 2$

Usually, $\mathrm{L}_{\min }$ is considered as constant while $\mathrm{L}_{\max }$ is analytically expressed using polynomial series as [17]:

$$
L_{\max }(i)=0.136-0.0045 i+0.0056 i^{2}-0.0022 i^{3}+0.00035 i^{4}
$$

From equations (6) and (7), one can deduce the following analytical expression of the electromagnetic torque:

$$
T_{k}=\frac{1}{2} i_{k}^{2} \cdot N_{r} L_{1} \cdot \sin \left(N_{r} \theta\right)
$$

Equation (9) shows the effect of parameter $L_{l}$ in calculating the torque, i.e. of the gap between the inductances $L_{\max }$ and $L_{\min }$ which we shall examine below.

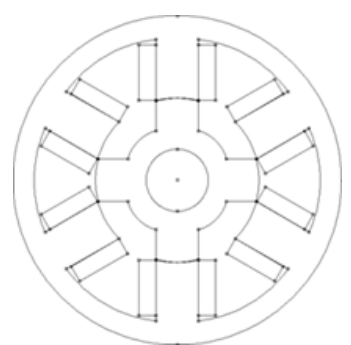

Figure 6. Diagram of the Studied 6/4 VRG

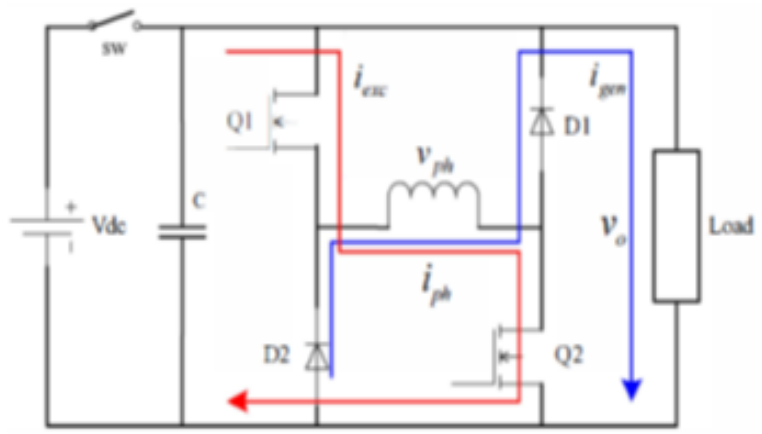

Figure 7. A Phase Circuit of VRG Fed by the Inverter

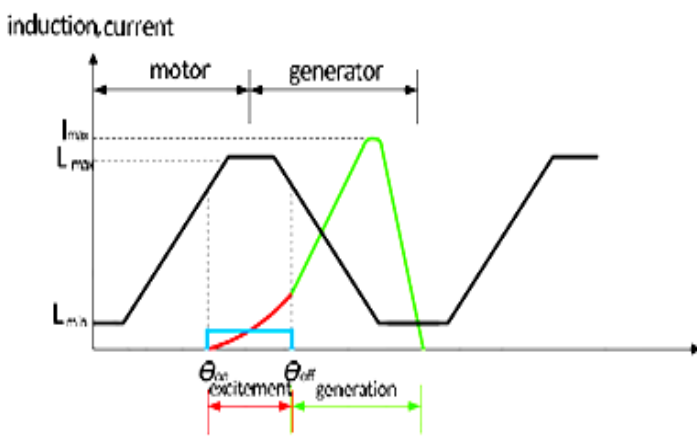

Figure 8. Motor and Generator Modes of the Variable Reluctance Machine 


\subsubsection{Numerical Model of Inductance by FEA}

Due to the high saturation of the magnetic circuit of the generator, it is very difficult to model analytically the different characteristics. Thus, a 2-D non-linear finite element model using FEMM software is performed. The schemes of magnetic flux density at the two extreme postions of rotor are depicted in Figure 9. The finite element analysis (FEA) of the studied generator, with parameters given in Table 3, allowed us to represent, as a function of the position and the current, the characteristics of linkage flux in Figure 10 and inductance in Figure 11. In addition, the data given by the FEA are stored in a matrix in order to build the look-up tables for 46 rotor positions, from $45^{\circ}$ to $90^{\circ}$, correspondind to the decreasing inductance (generator mode) and 6 different current values, from 0 to 10 A. Using MATLAB Look-up Table bloc, one could plot the 3-D curves shown in Figure 12 and Figure 13.

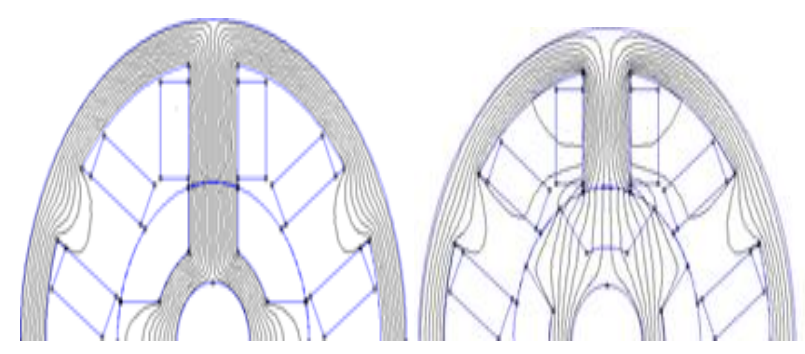

Figure 9. Plot of Magneticflux at Aligned and Unaligned Postions of Rotor

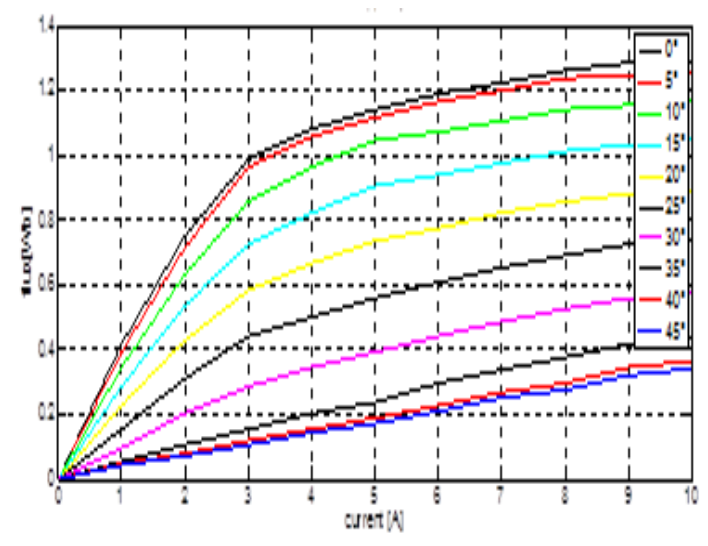

Figure 10. Linkage Flux vs. Current at different Rotor Positions

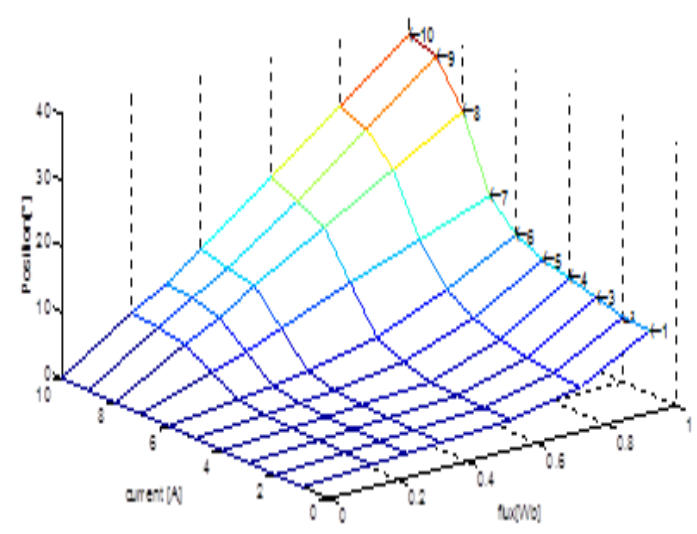

Figure 12. Flux/Position/Current Characteristic

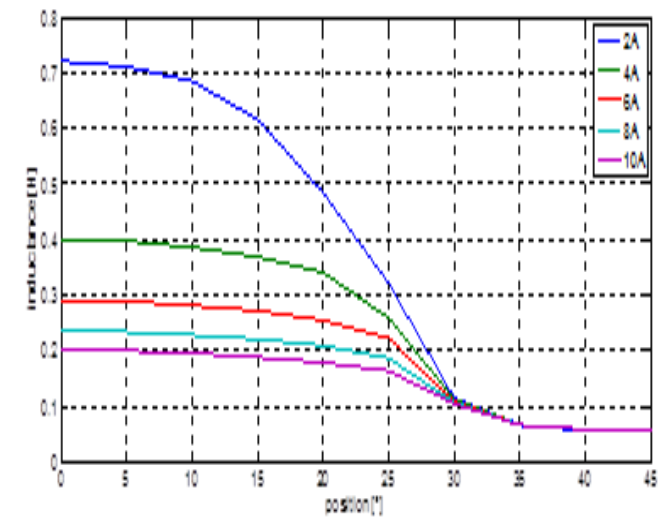

Figure 11. Inductance vs. Rotor Position at different Currents

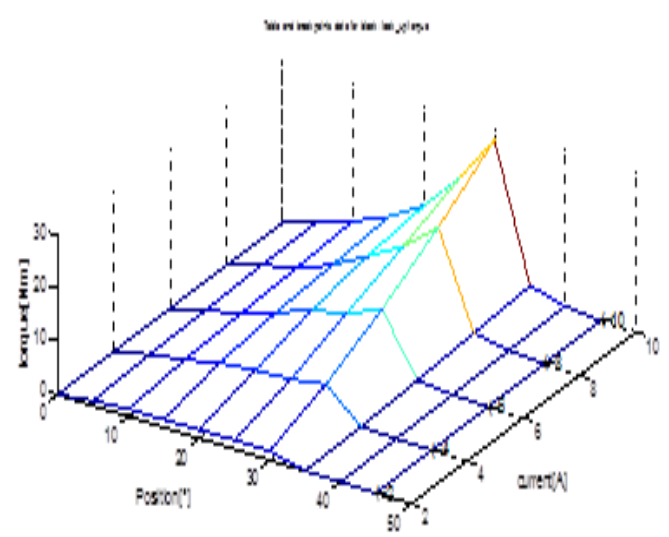

Figure 13. Current /Position/Torque Characteristic 
Table 3. Parameters of VRG

\begin{tabular}{cc}
\hline Parameter & Value \\
\hline Number of stator poles & 6 \\
Number of rotor poles & 4 \\
Outer diameter & $228.4 \mathrm{~mm}$ \\
Rotor bore diameter & $114.2 \mathrm{~mm}$ \\
Air-gap length & $0.25 \mathrm{~mm}$ \\
Shaft diameter & $40 \mathrm{~mm}$ \\
Stator pole angle & $30 \mathrm{deg}$ \\
Rotor pole angle & $30 \mathrm{deg}$ \\
\hline
\end{tabular}

\section{SIMULATION RESULTS OF WECS UNDER MATLAB/SIMULINK}

\subsection{Simulation of the Turbine and Gearbox}

Based on equations (1) to (4) representing the mathematic model of the turbine, we conctructed the Simulink diagram shown in Figure 14. The coupling turbine-gearbox with a gear ratio K is depicted in Figure 15.

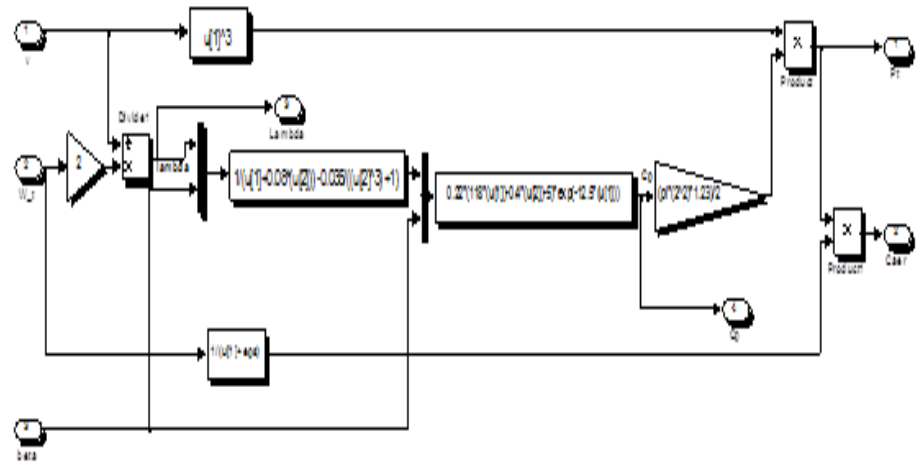

Figure 14. Model of the Turbine under Simulink

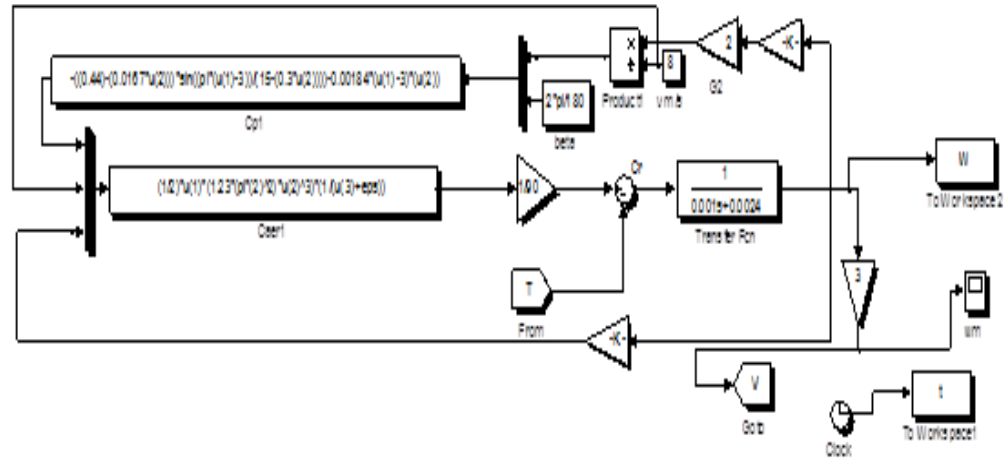

Figure 15. Bloc Diagram of the Wind Turbine and Gear Box

\subsection{Simulation of the Generator}

The simulink diagram model for the studied generator is shown in Figure 16. For simplifying the simulation process, we took the same parameters in all phases, we neglect the mutual inductance, eddy effect and hysteresis phenomena, and we assume that all switches of the inverter are ideal. As depicted in Figure 17, the ultimate model of the generator contains several modules such as the three phases of the VRG, the power inverter and its controllers. As mentioned previously, each phase contains the same parameters while the stator windings are detailed in Figure 18 with an angular shift of $120^{\circ}$ between them.

For starting the simulation process, we compute the position (the mechanical angle of the rotor) from an integration of the speed, taking in account the original angle of the rotor when the simulation starts as shown in Figure 19. The modeled torque equation using simulink is represented in Figure 20. The power inverter contains three blocks, an exciting source and a load as depicted in Figure 21. Each block of the inverter is represented in Figure 22. 


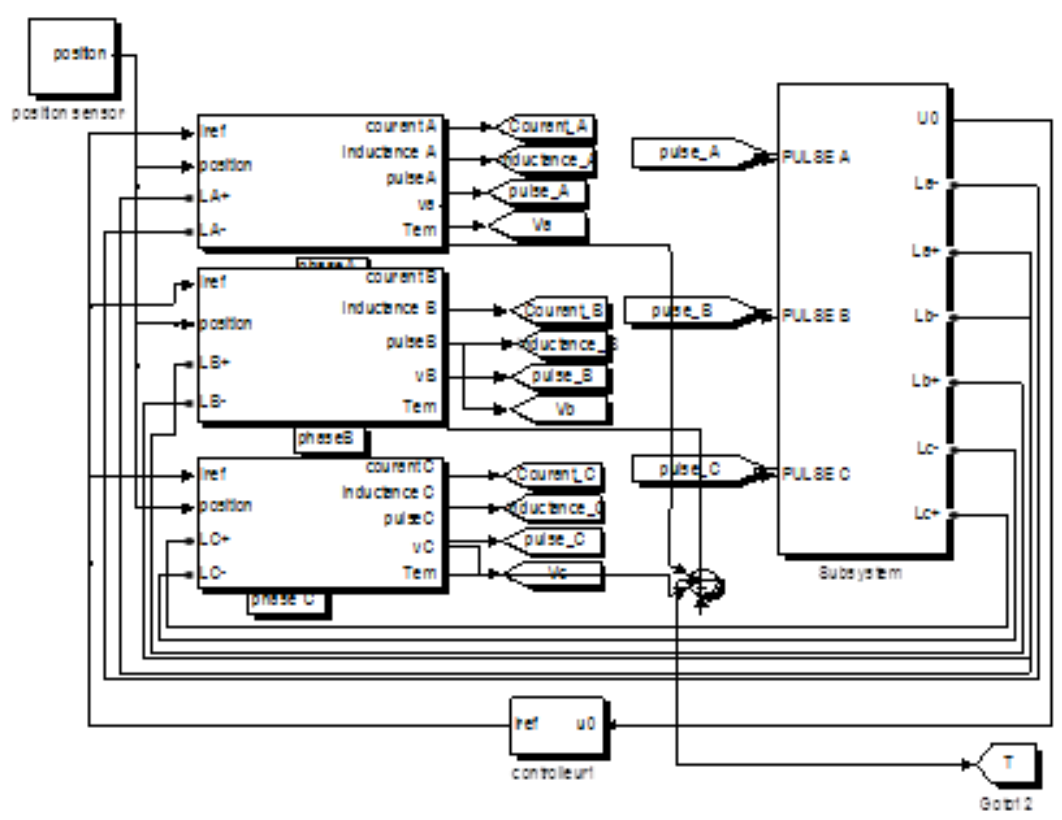

Figure 16. Simulink Diagram of the Studied VRG

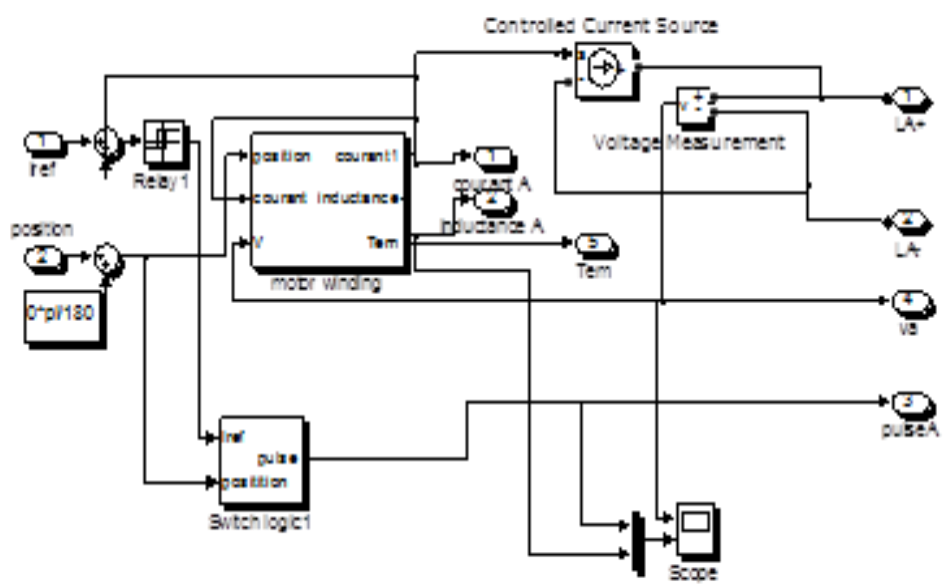

Figure 17. Blocs of One Phase of the Machine

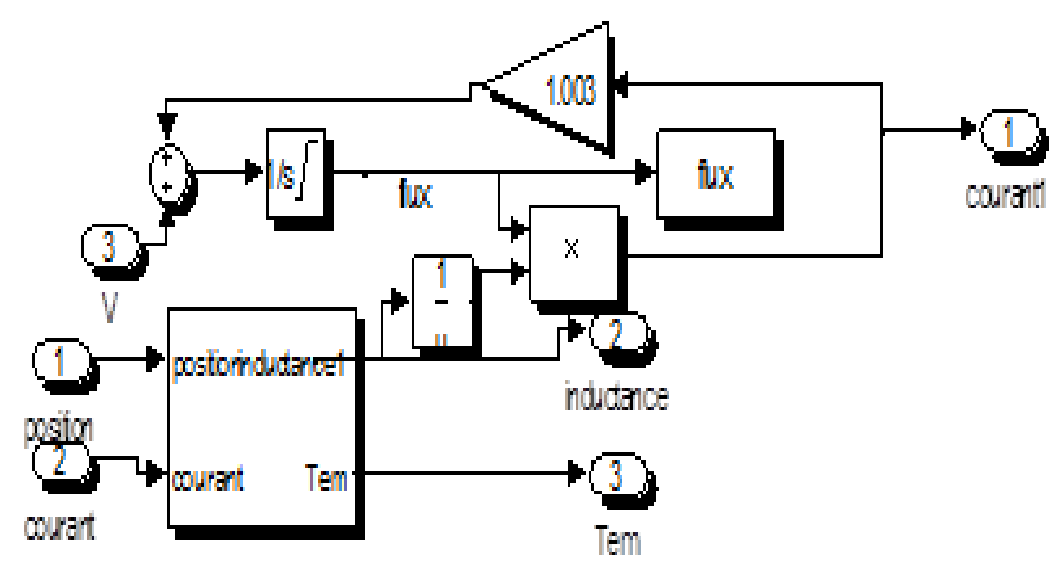

Figure 18. Bloc Diagram of Calculating the Inductance of Phase Winding 


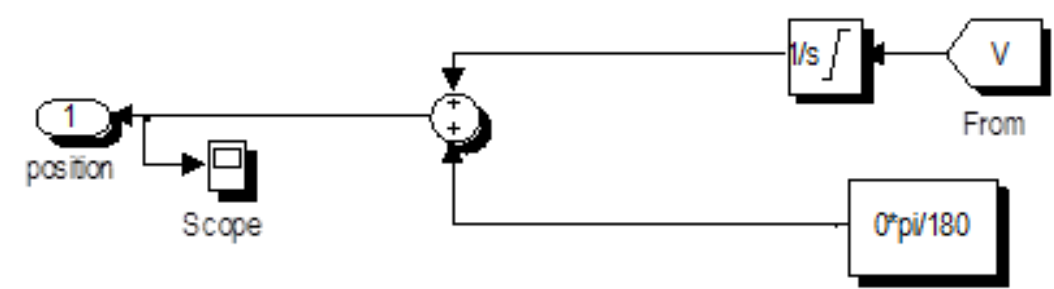

Figure 19. Bloc Diagram of the Position Sensor

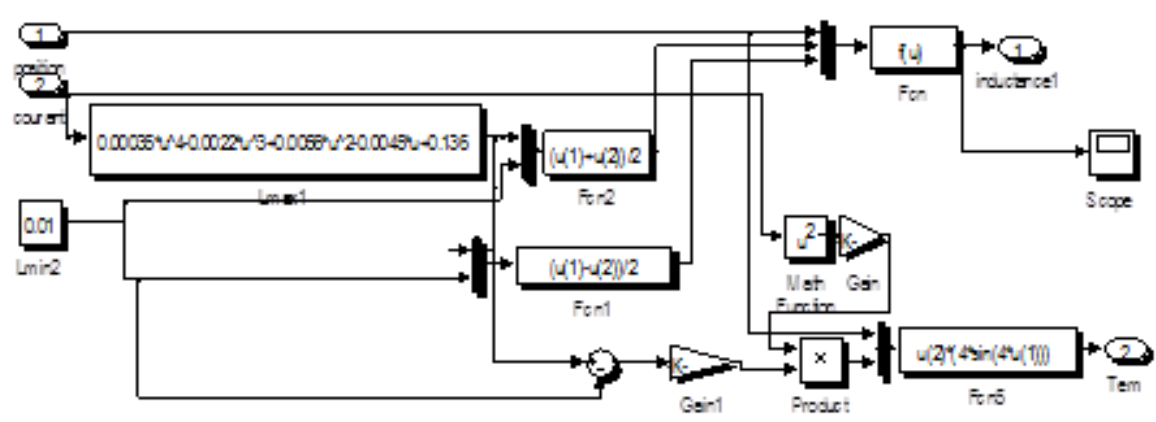

Figure 20. Bloc Diagram of Calculating the Electromagnetic Torque

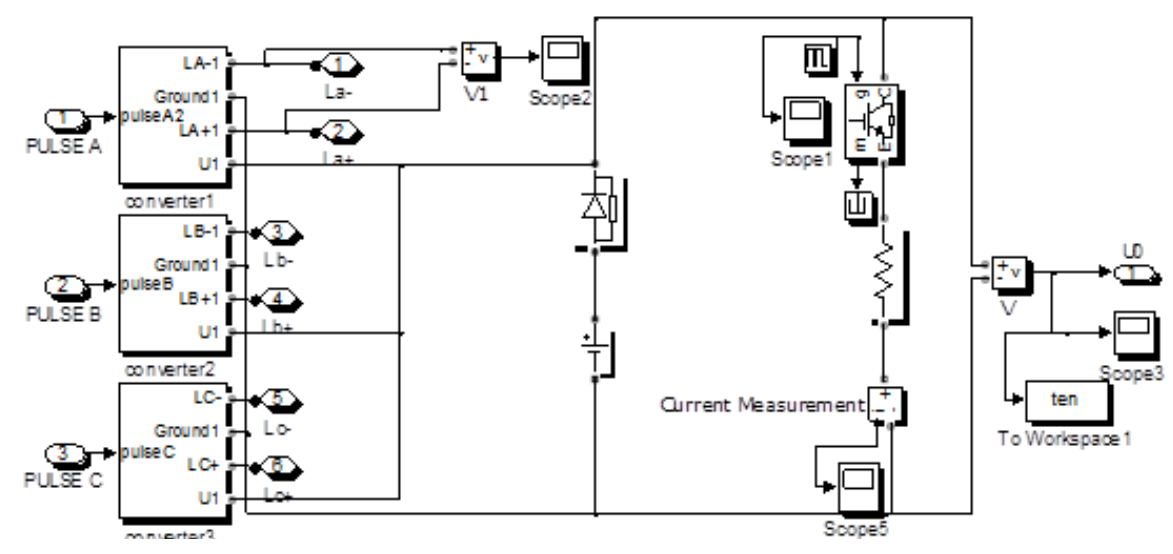

Figure 21. Bloc Diagram of the Inverter

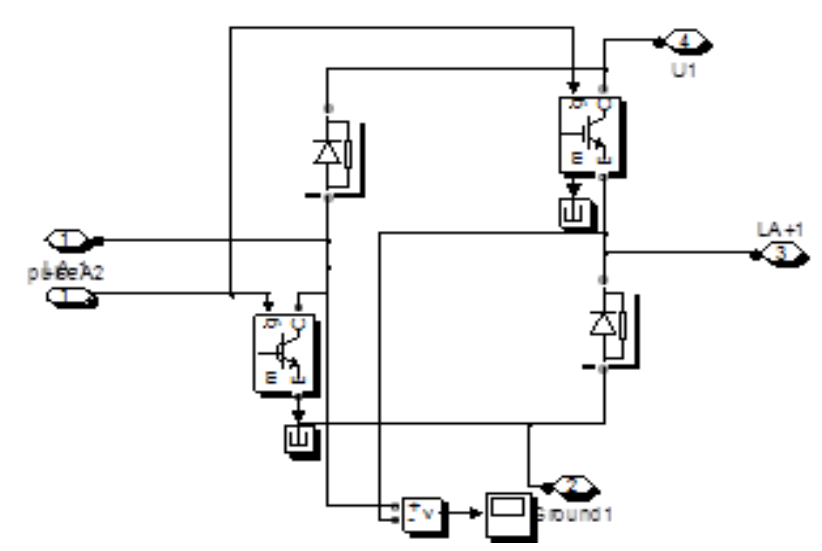

Figure 22. Bloc Diagram of an Inverter arm 


\subsection{Discussion of Results}

For getting high performances of the machine, the control bloc must work respectively to a specified turn-on angle $\left(\Theta_{\text {on }}=40^{\circ}\right)$ and turn-off angle $\left(\Theta_{\text {off }}=60^{\circ}\right)$. To validate our model, we have used the same conditions of simulation and same parameters as in [17]. The dynamic waveforms of currents and voltages in the three phases of the generator are depicted in Figure 23 and Figure 24 respectively. The converted energy by the proposed system can be estimated using the flux-current curve as represented in Figure 25 . The dynamic waveforms of the currents at different values of the turn-off angle $\Theta_{\text {off }}$ are shown in Figure 26. All these results confirm the validity of our model compared to the work of S. Song and W. Liu [17] and allow us to consider other development prospects.

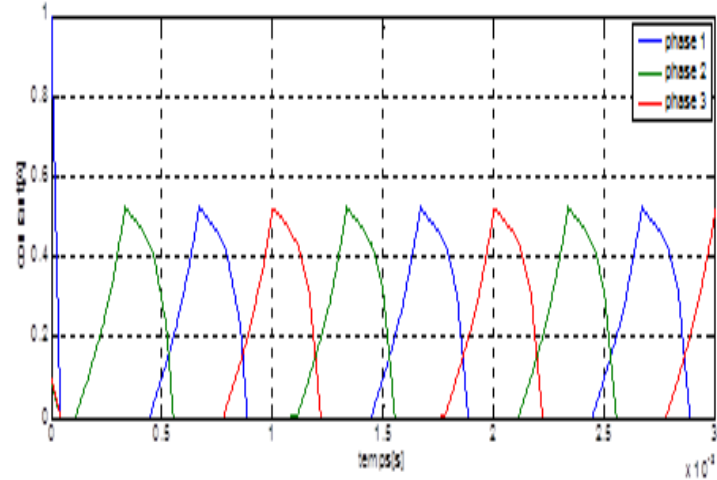

Figure 23. Dynamic Currents in the Three Phases

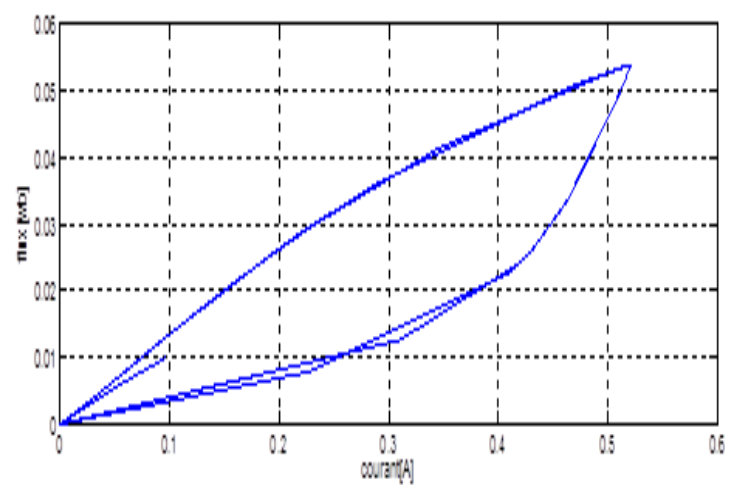

Figure 25. Flux vs. Current Diagram

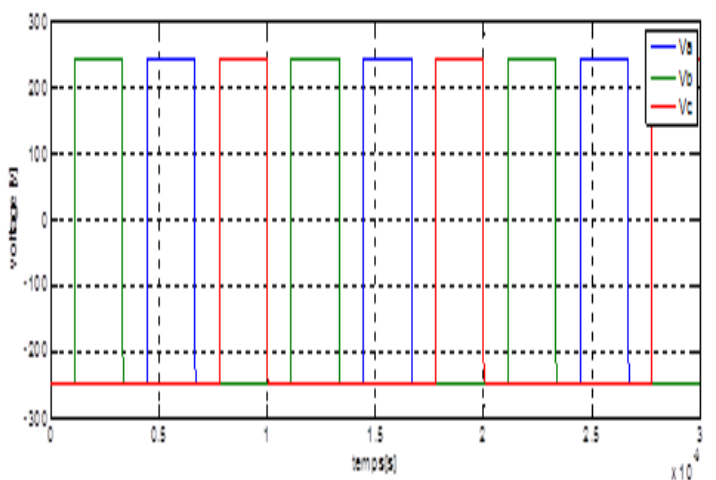

Figure 24. Dynamic Voltages in the Three Phases

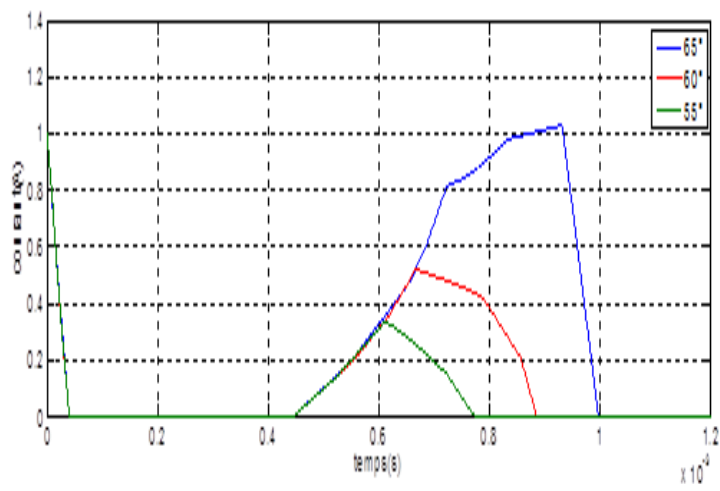

Figure 26. Dynamic Current for different $\theta_{\text {off }}$ Values

\section{CONCLUSION}

This work allowed us to model and simulates a variable speed wind turbine associated conveniently with gearless variable reluctance generator. This objective has been achieved using a user-friendly program coupling the open source software FEMM with MATLAB/SIMULINK widely used by the academic community. Another contribution of this work lies in the calculation by the finite element method of inductances at aligned and unaligned position. This allowed us to carry out a detailed analysis of system performances. It gave good results in dynamic non-linear generator operation. Currently, there are a little research results in this field; a continuation to the work would be followed to optimize the system performance by developing efficient control strategies.

\section{REFERENCES}

[1] K. Trinada, et al., "Study of Wind Turbine based SEIG under Balanced/Unbalanced Loads and Excitation," International Journal of Electrical and Computer Engineering, vol/issue: 2(3), pp. 353-370, 2012.

[2] A. M. Thin and N. S. Y. Kyaing, "Performance Analysis of Doubly Fed Induction Generator Using Vector Control Technique," International Journal of Electrical and Computer Engineering, vol/issue: 5(5), pp. 929-938, 2015. 
[3] T. Z. Khaing and L. Z. Kyin, "Control Analysis of Stand-Alone Wind Power Supply System with Three Phase PWM Voltage Source Inverter and Boost Converter," International Journal of Electrical and Computer Engineering, vol/issue: 5(4), pp. 798-809, 2015.

[4] S. M. Mohiuddin and M. R. I. Sheikh, "Stabilization of Solar-Wind Hybrid Power System by Using SMES," International Journal of Electrical and Computer Engineering, vol/issue: 4(3), pp. 351-358, 2014.

[5] A. Lebsir, et al., "Electric Generators Fitted to Wind Turbine Systems: An Up-to-Date Comparative Study," Journal of Electrical Systems, vol/issue: 11(3), pp. 281-295, 2015.

[6] H. Tiegna, et al., "Overview of High Power Wind Turbine Generators," in IEEE ICRERA, Nagasaki, Japan, pp. 16, 2012.

[7] A. Lebsir, et al., "Comparative Study of PMSM and SRM capabilities," in IEEE POWERENG, Istanbul, Turkey, pp. 760-763, 2013.

[8] H. Chen, "Implementation of a three-phase switched reluctance generator system for wind power applications," in IEEE SELT, Victoria, pp. 1-6, 2008.

[9] Y. Fan, et al., "A New Three-Phase Doubly Salient Permanent Magnet Machine for Wind Power Generation," in IEEE Trans. On Industry Applications, vol/issue: 42(1), pp. 53-60, 2006.

[10] R. Cardenas, et al., "Control of a Switched Reluctance Generator for Variable-Speed Wind Energy Applications," in IEEE Trans. On Energy Conversion, vol/issue: 20(4), pp. 781-791, 2005.

[11] V. B. Koreboina and L. Venkatesha, "Modelling and Simulation of Switched Reluctance Generator Control for Variable Speed WECS," in IEEE PEDES, Bengaluru, pp. 1-6, 2012.

[12] H. Chen, et al., "Research on the switched reluctance wind generator system," in IEEE PESGM, pp. 1-6, 2001.

[13] K. Ogawa, et al., "Study for Small Size Wind Power Generating System Using Switched Reluctance Generator," in IEEE International Conference on Industrial Technology, Mumbai, pp. 1510-1515, 2006.

[14] D. A. Torrey, "Switched Reluctance Generators and their Control," in IEEE Trans. On Industrial Electronics, vol/issue: 49(1), pp. 3-14, 2002.

[15] T. Benamimour, et al., "CAD of Electrical Machines Using Coupled FEMM-MATLAB Softwares," in IEEE EPECS, Istanbul, pp. 1-6, 2013.

[16] A. Soetedjo, et al., "Modeling of Wind Energy System with MPPT Control," in IEEE International conference on Electrical Engeneering and Informatics, Indonesia 17-19 July 2011.

[17] S. Song and W. Liu, "A Novel Method for Nonlinear Modeling and Dynamic Simulation of a Four-phase Switched Reluctance Generator System Based on MATLAB/SIMULINK," in IEEE ICIEA, Harbin, pp. 1509-1514, 2007. 